\title{
Nonblanchable erythema for predicting pressure ulcer development: a systematic review with an individual participant data metaanalysis
}

DOI:

10.1111/bjd.18154

\section{Document Version}

Accepted author manuscript

Link to publication record in Manchester Research Explorer

Citation for published version (APA):

Shi, C., Bonnett, L. J., Dumville, J. C., \& Cullum, N. (2019). Nonblanchable erythema for predicting pressure ulcer development: a systematic review with an individual participant data metaanalysis. British Journal of Dermatology, 182(2), 278-286. https://doi.org/10.1111/bjd.18154

\section{Published in:}

British Journal of Dermatology

\section{Citing this paper}

Please note that where the full-text provided on Manchester Research Explorer is the Author Accepted Manuscript or Proof version this may differ from the final Published version. If citing, it is advised that you check and use the publisher's definitive version.

\section{General rights}

Copyright and moral rights for the publications made accessible in the Research Explorer are retained by the authors and/or other copyright owners and it is a condition of accessing publications that users recognise and abide by the legal requirements associated with these rights.

\section{Takedown policy}

If you believe that this document breaches copyright please refer to the University of Manchester's Takedown Procedures [http://man.ac.uk/04Y6Bo] or contact uml.scholarlycommunications@manchester.ac.uk providing relevant details, so we can investigate your claim.

\section{OPEN ACCESS}


MR CHUNHU SHI (Orcid ID : 0000-0003-0151-0451)

Article type : Original Article

\section{Non-blanchable erythema for predicting pressure ulcer development: a systematic review with an individual participant data meta-analysis}

C. Shi ${ }^{1}$, L.J. Bonnett ${ }^{2}$, J.C. Dumville ${ }^{1}$, N. Cullum ${ }^{1,3}$

1 Division of Nursing, Midwifery \& Social Work, School of Health Sciences, Faculty of Biology,

Medicine \& Health, University of Manchester, Manchester Academic Health Science Centre,

Manchester, UK, M13 9PL

2 Department of Biostatistics, University of Liverpool, Waterhouse Building, Block F, 1-5 Brownlow Street, Liverpool, UK, L69 3GL

3 Research and Innovation Division, Manchester University NHS Foundation Trust, Manchester Academic Health Science Centre, 1st Floor, Nowgen Building, 29 Grafton Street, Manchester, UK, M13 9WU

\section{Correspondence to}

Chunhu Shi

Division of Nursing, Midwifery \& Social Work, University of Manchester,

Manchester, UK, M13 9PL

E-mail: chunhu.shi@postgrad.manchester.ac.uk (CS)

This article has been accepted for publication and undergone full peer review but has not been through the copyediting, typesetting, pagination and proofreading process, which may lead to differences between this version and the Version of Record. Please cite this article as doi: $10.1111 /$ bjd. 18154

This article is protected by copyright. All rights reserved. 
Running head: Non-blanchable erythema for predicting pressure ulcer risk

\section{Funding sources}

This research was funded by the President's Doctoral Scholar award of the University of Manchester (CS) and supported by the NIHR Manchester Biomedical Research Centre. The funder had no role in study design, data collection and analysis, decision to publish, or preparation of the manuscript.

\section{Conflict of interest}

The authors declare that they have no competing interests.

\section{What's already known about this topic?}

- Pressure ulcer reduction is a high priority for healthcare systems. Regularly inspecting skin to identify skin abnormalities is one key practice of preventing ulceration.

- Non-blanchable erythema - the discolouration of the skin that does not turn white when pressed is one of clinically important skin abnormalities.

- Empirical evidence synthesised using conventional meta-analysis is uncertain regarding the value of non-blanchable erythema for predicting open pressure ulcer incidence partly because the conventional technique has weakness in terms of pooling prognosis effects of different multivariable analyses across studies.

\section{What does this study add?}

- The prognostic factor review - using individual-level data analysis to overcome the limitation of conventional meta-analysis technique - for the first time adds confirmatory and moderatecertainty evidence on the association of non-blanchable erythema with pressure ulcer incidence to current evidence base.

- People with non-blanchable erythema are more likely to develop new pressure ulcers of Stage 2 or severe within 28 days than people without non-blanchable erythema regardless of their age, baseline pressure ulcer risk or received support surfaces. 


\title{
Non-blanchable erythema for predicting pressure ulcer development: a systematic review with an individual participant data meta-analysis
}

\begin{abstract}
Background: Empirical evidence is uncertain regarding the value of non-blanchable erythema in predicting Stage 2 (or more severe) pressure ulcer incidence. We aimed to investigate whether nonblanchable erythema is an independent prognostic factor for pressure ulcer incidence using individual patient data.
\end{abstract}

Methods: We performed an electronic database search in February 2017 to identify longitudinal studies that considered non-blanchable erythema for predicting pressure ulcer risk in any population. We collected individual participant data for the included studies, and assessed risk of bias of these studies using the Quality In Prognosis Studies tool. We analysed individual participant data in STATA using mixed-effects logistic regression for investigating the association of our interest. The certainty of evidence from individual participant data analysis was assessed using the Grades of Recommendation Assessment, Development and Evaluation.

Results: Of the thirteen included studies (68,077 participants), we had access to individual participant data from four $(n=3,223)$ and $11.88 \%$ of participants $(383 / 3,223)$ developed new pressure ulcers of Stage 2 or above within 28 days. Mixed-effects logistic regression showed that participants with nonblanchable erythema had higher odds of developing new pressure ulcers of Stage 2 or above within 28 days of follow-up than those without non-blanchable erythema (multivariable association: $n=2,684$; OR $2.72,95 \%$ CI 2.02 to 3.69 ; tau-squared $=0$; moderate-certainty evidence).

Conclusions: The first prognostic factor review with individual-level data analysis in pressure ulcers suggests people with non-blanchable erythema are more likely to develop new pressure ulcers of Stage 2 or above within 28 days than people without non-blanchable erythema. It is important to identify non-blanchable erythema in practice and intervene appropriately to prevent pressure ulceration.

This article is protected by copyright. All rights reserved. 
Registration: PROSPERO (CRD42017081151)

\section{Keywords}

Pressure ulcer, non-blanchable erythema, prognostic factor review, individual participant data analysis

\section{Introduction}

Pressure ulcers (also known as pressure injuries, and decubitus ulcers) are localised injuries to skin and underlying tissue, ${ }^{1}$ primarily caused by pressure or shear on the skin. Pressure ulcers are prevalent in approximately 3.1 per 10,000 people in the general United Kingdom (UK) population, ${ }^{2}$ and in between 470 and 3,210 per 10,000 hospitalised patients in the UK, United States, and Canada. ${ }^{3}$

Non-blanchable erythema (i.e. Stage 1 ulcer) is intact skin with intractable redness in a localised area, and is conventionally regarded as an early sign of pressure ulceration. ${ }^{1}$ From a pathophysiological perspective, the superficial damage of non-blanchable erythema-if continuously exposed to pressure and/or shearing forces - may deteriorate until the occurrence of open (Stage 2 or worse) pressure ulcers that affect underlying tissues. ${ }^{4}$

Non-blanchable erythema is reversible, ${ }^{1}$ thus not all individuals with non-blanchable erythema will necessarily develop an open pressure ulcer. Conversely since some pressure ulceration starts with abnormalities of the deep tissue rather than superficial skin $^{4}$ not all ulcers will be preceded by nonblanchable erythema. Empirical evidence is uncertain on the association of non-blanchable erythema with pressure ulcer incidence..$^{5}$ In this review, we aimed to investigate whether non-blanchable erythema is an independent prognostic factor for pressure ulcer incidence using individual participant data analysis.

\section{Methods}

This review, prospectively registered with PROSPERO (CRD42017081151), follows the Preferred Reporting Items for a Systematic Review and Meta-analysis of Individual Participant Data (PRISMAIPD) reporting guidance. ${ }^{6}$ 


\section{Eligibility criteria}

Eligible studies were prospective and retrospective longitudinal studies that applied multivariable analysis to evaluate the independent effects of multiple factors on pressure ulcer incidence in any population. ${ }^{7}$ Because multiple prognostic factors may be associated with pressure ulcer incidence, ${ }^{8}$ we excluded studies that considered non-blanchable erythema as the sole prognostic factor (univariable analysis).

\section{Search strategy}

Using comprehensive search strategies that combined terms for pressure ulcer ${ }^{9}$ with published prognosis study search filters, ${ }^{10-13}$ we searched Ovid MEDLINE and EBSCO CINAHL Plus in $14^{\text {th }}$ February 2017 without any restriction. We also searched ProQuest for relevant doctoral theses and screened the reference lists of eight relevant systematic reviews, ${ }^{8,14-20}$ as well as of potentially eligible studies.

\section{Study selection}

The titles and abstracts of all citations were screened by two reviewers independently. One reviewer then inspected the full texts of all potentially eligible studies and a second reviewer independently judged the eligibility of $10 \%$ of the potentially eligible studies (random sample). Disagreements were resolved by discussion between two reviewers and involvement of a third reviewer if necessary.

\section{Data collection}

We requested anonymised individual participant data for all eligible studies via e-mail with corresponding authors. Individual participant data at baseline were requested for the factors that (1) were reported to have possible associations with pressure ulcer incidence in literature; (2) can be easily obtainable in practice; (3) and can fit the conceptual frameworks of pressure ulcer development. ${ }^{21-23}$ See Appendix file 1 for the list of these factors.

Received data were combined into a single data set; where necessary, data were cleaned following suggestions of Schmid. ${ }^{24}$ For example, we imputed data for "the use of support surfaces" factor: if the use of support surfaces was described in study reports (e.g., an example case: all participants used 
higher-specification foam mattress or gel mattress), all individuals were imputed to have used the named support surfaces. We also extracted study-level data from included papers using a prespecified data extraction form as we reported in the paper related to this review. ${ }^{5}$

\section{Risk of bias assessment}

We undertook risk of bias assessment using the adapted Quality In Prognosis Studies (QUIPS) tool (see Appendix file 2 Table S1). ${ }^{25}$ Each risk of bias domain was judged as low, unclear or high risk of bias by one reviewer. ${ }^{25}$ A second reviewer checked all assessments independently. Any discrepancy between two reviewers was resolved by discussion and a third reviewer was involved where necessary.

\section{Data synthesis}

\section{Methods for individual participant data analysis}

We described the characteristics of participants using appropriate descriptive statistics (mean and standard deviation (SD), or number and percentage) and did exploratory tests ( $\mathrm{t}$ test, ANOVA and chisquared test) where necessary (1) to evaluate whether the data of each variable, where reported, were distributed similarly between the studies with individual-level data and those with aggregate data; and (2) to evaluate if potential clinical heterogeneity existed in individual participant data analysis through comparing the data distribution for each variable between the studies with individual-level data.

Using one-stage individual participant data meta-analysis, we performed the following mixed-effects models where random intercepts were assumed to account for clustering: (1) including nonblanchable erythema only in a univariable random coefficients logistic regression to evaluate the univariable association; (2) including non-blanchable erythema and other factors (those with more than $80 \%$ of data across studies ${ }^{26}$ but not correlated with others ${ }^{27}$ ) to perform a multivariable random coefficients logistic regression. ${ }^{28}$ All factors selected above were included in the multivariable model without any elimination. ${ }^{29}$ Of the included factors, non-blanchable erythema was assumed to have random-effects across studies, whilst other factors were assumed to have fixed-effects; continuous 
factors were transformed via restricted cubic splines to consider the potential non-linear relationships between them and pressure ulcer incidence. ${ }^{27}$ We used an unstructured covariance matrix in the modelling. ${ }^{30}$

We performed the main analysis based on complete cases. In the case of missing data, we applied multiple imputation using chained equations (MICE)-with ten imputations in a sensitivity analysis. ${ }^{31}$ As for missing data at the study level, i.e., where a study did not collect data on specific factors, we pooled only studies with available data on specific factors because available imputation methods are still under development and not widely applied. ${ }^{32,33}$

All analyses were conducted using STATA (Version 14.0, StataCorp, College Station, Texas). Odds ratios (ORs) and 95\% confidence intervals (CIs) were presented for the pooled results. A significance level of (two-sided p-value) 0.05 was used. For continuous factors that were transformed with restricted cubic spline, we present the post-estimation results for some selected values of each factor and display the non-linear relationships graphically. The Grades of Recommendation Assessment, Development and Evaluation (GRADE) was used to assess the certainty of evidence from the individual participant data meta-analysis. ${ }^{34}$

We performed pre-planned additional analyses (see Appendix file 3): (1) analyses to investigate the interaction effects of three potential confounders (age, ${ }^{35}$ baseline pressure ulcer risk, ${ }^{36,37}$ and the use of support surfaces ${ }^{22}$ ) in multivariable model; (2) one sensitivity analysis to explore the impact of follow-up duration and another to explore the impact of missing data. We also assessed publication bias.

\section{Methods for aggregate data meta-analysis}

We used generic inverse variance meta-analysis with a random-effects model to pool the aggregate data (ORs and variances) across studies. We then compared aggregate data analysis with individual participant data analysis to examine the consistency of both analysis results. 


\section{Results}

\section{Characteristics of included studies}

Of 6,908 records identified through literature search, we included 13 studies (associated with 16 publications) in this review ${ }^{38-53}$ (see Fig. 1).

See Appendix file 4: Table 2 for the characteristics of these studies. Of the thirteen included studies, ten were conducted in hospital settings and three were in nursing homes/long-term facilities. ${ }^{44-46}$ The thirteen studies involved 68,077 participants. Individual-level data for 64,757 participants from eight studies were unavailable (for reasons provided in Fig. 1); Of these eight studies with data unavailable, three (involving a majority of participants included in this review, $n=59,214$ ) applied American population healthcare data registries as data sources ${ }^{43-46}$ where data were not collected specifically for any research and were not expected to be available due to legitimate issue. The authors of five studies $(\mathrm{n}=3,320)$ agreed to share their individual participant datasets, of which four $(\mathrm{n}=3,223)$ could be used in the subsequent analyses in this review ${ }^{40,41,47-49,51,52}$ because one data set was not transferred. ${ }^{38}$

Table 1 shows the characteristics of participants in each study and across the four studies. The mean (SD) age of 3,223 participants was 75.35 (11.94) years, which did not differ significantly from the mean age of participants in the unavailable studies $(73.96$, SD 12.79) $(\mathrm{t}$ test $\mathrm{p}$-value $=0.23)$. Of the 3,223 participants, $62.27 \%$ were female $(2,007)$, which was higher than the proportion of females (31.21\%) in the studies without available individual participant data (chi-squared test p-value < $0.001)$.

\section{Table 1: The characteristics of participants within and across the included studies}

At baseline, $22.12 \%$ of participants $(713 / 3,223)$ had non-blanchable erythema; among $98.45 \%$ of participants $(3,173 / 3,223)$ with baseline Braden scores, $87.61 \%(2,780 / 3,173)$ were judged at risk of developing pressure ulcers with a Braden score $\leq 18$ as the criterion of being 'at risk'. The incidence of new pressure ulcers of Stage 2 or above within 28 days of follow-up was $11.88 \%(383 / 3,223)$. The stage of ulcers was specified in 51.13\% of participants (192/383) with incident ulcers; $97.39 \%$ 
(187/192) were Stage 2 ulcers and 2.60\% (5/192) were Stage 3. When participants with incident ulcers beyond 28 days were counted, $12.47 \%(417 / 3,223)$ developed a new pressure ulcer of Stage 2 or above at any time.

\section{Risk of bias assessment}

The four studies with individual participant data were judged as low risk of bias for all domains $^{40,41,47,48}$ or as unclear risk of bias for one domain. ${ }^{49,51,52}$ See Figure 2 for all risk of bias assessments.

\section{Individual participant data analyses}

For the univariable association, mixed-effects logistic regression involving non-blanchable erythema alone showed that participants with non-blanchable erythema had 3.52 times the odds of developing new pressure ulcers of Stage 2 or above within 28 days compared with those without non-blanchable erythema (random coefficients model: $\mathrm{n}=3,223$; OR 3.52, 95\% CI 2.72 to 4.56 ; tau-squared $=0$; see Table 2). This evidence is low-certainty, downgraded twice for strongly suspected publication bias, but upgraded once for a moderate effect size. This means that if we assume 77 people per 1,000 without non-blanchable erythema develop new pressure ulcers of Stage 2 or above within 28 days, 227 people per 1,000 (95\% CI 185 to 275 ) with non-blanchable erythema might be expected to develop new ulcers.

\section{Table 2: Results of univariable and multivariable multilevel analyses using complete cases and}

\section{imputed data}

In the multivariable model including non-blanchable erythema, and nine additional variables, participants with non-blanchable erythema had 2.72 times the odds of developing a new pressure ulcer of Stage 2 or above within 28 days compared with those without non-blanchable erythema (random coefficients model: $\mathrm{n}=2,684$; OR 2.72, 95\% CI 2.02 to 3.69; tau-squared $=0$; see Table 2). This evidence is moderate-certainty, downgraded twice for strongly suspected publication bias and upgraded once for a moderate effect size and once for plausible confounding. This suggests that if we assume 73 people per 1,000 without non-blanchable erythema develop new pressure ulcers of Stage 2 
or above within 28 days, 176 people per 1,000 (95\% CI 137 to 225) with non-blanchable erythema will probably develop new ulcers.

\section{Estimation of effect modifications (interactions)}

None of the three pre-planned interactions showed statistically significant results, meaning that participants with non-blanchable erythema had higher pressure ulcer risk than those without nonblanchable erythema regardless of their age, Braden scores or received support surfaces (see Appendix files 8-10: Figs S4 to S6).

\section{Sensitivity analyses}

Appendix file 11 Table S3 suggested that ignoring the missing data $(539 / 3,223)$ might result in bias. The analysis with ten multivariable imputations of missing data was conducted, suggesting a significant multivariable association of non-blanchable erythema and pressure ulcer incidence $(\mathrm{n}=$ 3,183; OR $2.70,95 \%$ CI 2.08 to 3.52). Another sensitivity analysis using data on pressure ulcers of Stage 2 or above at any time also showed a significant association of non-blanchable erythema and pressure ulcer incidence $(\mathrm{n}=2,684$; OR $2.77,95 \%$ CI 2.05 to 3.75$)$.

\section{Publication bias}

The literature search was comprehensive. We did not produce a funnel plot to for excluding the possibility of publication bias because only four data sets (the small volume of individual participant data: $4.73 \%, 3,223 / 68,077)$ were included in the analysis.

\section{Aggregate data meta-analyses compared with individual participant data analyses}

For univariable association, meta-analysis using aggregate data from three studies without individual participant data ${ }^{38,39,50}$ suggested that non-blanchable erythema was associated with increased odds of pressure ulcer incidence (random-effects model: $\mathrm{n}=4,485$; $\mathrm{OR}=5.12,95 \%$ CI 3.21 to $8.17 ; I^{2}=$ $67.6 \%)$.

For multivariable association, meta-analysis with aggregate data from six studies without individual participant data ${ }^{42,44-46,50,53}$ showed that participants with non-blanchable erythema had 2.23 times higher the odds of developing new pressure ulcers than those without non-blanchable erythema 
(random-effects model: $\mathrm{n}=62,718$; OR $2.23,95 \%$ CI 2.02 to $2.46 ; I^{2}=75.7 \%$ ). Both above metaanalyses are consistent with the corresponding individual participant data analyses.

\section{Discussion}

\section{Main findings}

We have conducted this review with meta-analysis of individual participant data $(n=3,223)$ to summarise the evidence on the prognostic value of non-blanchable erythema for predicting pressure ulcer development. Moderate-certainty evidence from multivariable analysis suggests that 103 more people with non-blanchable erythema (95\% CI 64 to 152 more) per 1,000 will probably develop new pressure ulcers of Stage 2 or above within 28 days than those without non-blanchable erythema. Nonblanchable erythema will be predictive for pressure ulcer incidence without any distinction between older and younger participants, between lower and higher Braden scores and between active air mattress use and reactive mattress use. Given the characteristics of participants whose data were available for analysis, evidence in this review is expected to be applicable for older-particularly female-inpatients.

\section{Comparison with previous reviews}

We could not identify any previous systematic review quantifying the prognostic association of nonblanchable erythema and pressure ulcer incidence, except for a systematic review we have published. ${ }^{5}$ Our previous review pooled study-level data to investigate the prognostic associations of 15 skin status descriptors (including non-blanchable erythema) and pressure ulcer incidence. For nonblanchable erythema, meta-analysis of multivariable data from nine studies suggested substantial heterogeneity $\left(\mathrm{I}^{2}=72.1 \%\right)$ that was not explained by sub-group analyses of study-level characteristics. Mainly due to, for example, the use of different sets of covariates across multivariable analyses of included studies, such a heterogeneity cannot be tackled via, for example, sub-group analysis technique related to aggregate data meta-analysis. ${ }^{5}$ The previous review concluded with lowcertainty evidence on the association of our interest, leaving considerable uncertainty. Our new study using individual participant data analysis adds important confirmatory evidence: firstly, evidence 
from individual participant data is more certain than evidence from aggregate data, which may be because individual participant data analysis (adjusting for the same set of covariates across studies) has a lower heterogeneity (tau-squared $=0$ ) than the aggregate data analysis. Secondly, nonsignificant findings of all interaction effects confirm the prognostic value of non-blanchable erythema for pressure ulcer development in different patient populations.

\section{Strengths and limitations of this review and analysis}

The first strength of this review is the application of individual participant data analysis to help overcome the issues of heterogeneity and incomplete reporting of multivariable results that occurred in the aggregate data meta-analysis. ${ }^{5,54}$ Using individual participant data allows us to use a consistent set of factors for adjustment of the prognostic effect and to examine non-linear relationships and interactions between factors. ${ }^{54}$ The second strength is the application of optimal evidence synthesis methods, e.g., a comprehensive literature search, the use of the QUIPS tool for risk of bias assessment.

The individual participant data analysis has some limitations. Firstly, it is difficult to know all factors that are associated with pressure ulcer incidence, thus it is unclear if we have factor selection bias in this work. To minimise the risk of such selection bias, we considered existing research evidence on specific prognostic factors of pressure ulcer incidence, ${ }^{8}$ the availability of factors in clinical practice, and the conceptual frameworks of pressure ulceration ${ }^{21-23}$ to determine the factors on which we requested data. Additionally we have to acknowledge that challenges exist in defining and retrieving potentially eligible types of studies for this review. Longitudinal studies should have been eligible regardless of univariate or multivariable analyses applied. However, given multiple factors are regarded to be contributory for pressure ulcer development, we reasonably required that eligible studies include multiple variables (including non-blanchable erythema). Studies using multivariable analysis can be prone to meet this requirement and have established approaches to retrieve them. If studies with univariate analysis were considered too, it can be expected the review and analysis could be extremely unmanageable and it is difficult to retrieve such studies. In order to avoid further bias, the eligibility of studies with multivariable analysis was pre-specified in our registered protocol. 
Secondly, due to reasons beyond our control, only a small portion of individual participant data were obtained in this analysis which might lead to biased prognostic results. ${ }^{55}$ One solution to tackle this problem is deriving aggregate data using individual participant data and then simply pooling them and aggregate data extracted from the studies without individual participant data available. ${ }^{55}$ This strategy was not followed because it has to synthesise both derived and extracted aggregate data using twostage approach. As a result, it shares the same issue of heterogeneity as the previous aggregate data meta-analysis, ${ }^{5}$ and disables the advantage of one-stage individual participant data analysis in terms of investigating heterogeneity. ${ }^{54}$ To improve this situation, we planned to re-construct individual-level data from aggregate level data where possible using the method suggested by Riley and Steyerberg. ${ }^{56}$ For example, if a study reported a contingency table that grouped the numbers of cases with or without non-blanchable erythema by pressure ulcer incidence, individual-level data can be reconstructed. However, this was not performed due to the incomplete reporting of aggregate data. Nonetheless, we applied two approaches to assess whether the results of individual participant data analysis based on part of eligible participants are trustworthy. (1) We checked the agreement regarding the characteristics between 3,223 participants and all 68,077 eligible participants; and exploratory analysis suggests participants with available data are generally representative for all participants. (2) We avoided ignoring the eight studies in which individual participant data are unavailable through assessing whether the results of the individual participant data analysis and the aggregate data meta-analysis of the eight studies are consistent. The consistency we found means that the unavailability of some data might not be a serious concern in this review. However, the potential for bias was acknowledged by our downgrading of the certainty of evidence due to possible publication bias.

Thirdly, ideally we would have implemented a single model to simultaneously address the issues of continuous and missing data under the framework of mixed-effects modelling using STATA. Morris et al. ${ }^{57}$ proposed a possible single model approach that employs a multiple fractional polynomial technique to handle continuous data and multiple imputation technique for missing data, but it does not support mixed-effects modelling. In this review, we used two stages to address the above issues: 
employing a restricted cubic spline method to identify non-linear terms of a continuous factor, and then, using MICE to impute missing data. The strategy was used in deriving the QRISK tool, ${ }^{58}$ and was considered as a practical alternative. In terms of addressing missing data at the study level, we decided to use complete case analysis in this review, that is, analysing only studies with full individual participant data on all variables (termed fully adjusted method) because other existing techniques are regarded inappropriate in the case of this review. One simple technique includes all studies in analysis but removes those variables without individual participant data available (termed partially adjusted method). As a result, variables of interest may lose part of the data, thus producing imprecise estimates. A technique, as the combination of fully and partially adjusted methods, has only been evaluated with two-stage analysis approach. ${ }^{33}$ A multiple imputation method includes all studies and adjusts for all variables. This method seems to be appropriate, however, it has only been evaluated for systematically imputing missing data for continuous variables. ${ }^{32}$

\section{Implications for current practice and future research}

Strong confirmatory evidence we produced in this review suggests that once erythema occurs in practice, care practitioners should confirm whether it is non-blanchable or blanchable. Once nonblanchable erythema is identified, people are probably at higher risk of developing new pressure ulcers and appropriate preventive measures should be provided in time to deter the progression towards a more severe pressure ulcer. ${ }^{59}$ As well as being of clinical importance, findings from this review highlight that non-blanchable erythema should be considered as an important prognostic factor in future prognostic models for pressure ulcer prediction. ${ }^{60}$ However, this evidence is based on clinical studies with high degrees of standardisation. Correctly identifying non-blanchable erythema in clinical practice is still a major challenge, for example, with low reliability as numerous studies suggest ${ }^{61,62}$. Future research can assess the reliability of potential methods (e.g., use of transparent disk, or finger test approach) used for measuring non-blanchable erythema.

The evidence in this review is largely applicable for predicting Stage 2 pressure ulcers because only a small proportion of participants in the studies included here $(2.60 \%, 5 / 192)$ developed Stage 3 ulcers. Given that Stage 3 and 4 ulcers may have different pathophysiological pathways from Stage 2 ulcers, ${ }^{4}$ 
future research should investigate whether non-blanchable erythema is predictive for ulcers of Stage 3 or above.

\section{Conclusions}

There is moderate-certainty evidence that people with non-blanchable erythema have more than twice the odds of developing new pressure ulcers of Stage 2 or above within 28 days than people without non-blanchable erythema regardless of their age, baseline pressure ulcer risk (Braden scores) or received support surfaces. This review offers empirical evidence to favour the React to Red Skin campaign - a campaign aiming to educate people in the community with simple knowledge about erythema for pressure ulcer prevention. ${ }^{63}$

\section{Acknowledgements}

We would like to thank Ms Sarah Rhodes for commenting on our study protocol. We like to acknowledge University of Leeds's contribution in the publication arising from the research: "NIHR PURPOSE Pain Cohort Study" (Reference 51), funded by the NIHR, and Professor Jane Nixon as the Chief Investigator. We also like to acknowledge Professor Dame Nicky Cullum who, as the Chief Investigator, supplied the individual participant data of "NIHR PRESSURE study" (References 40, 41), funded by the NIHR; Professor Maria Grypdonck, Professor Dimitri Beeckman and Dr Liesbet Demarré who helped to transfer individual participant data of their study (References 47, 48); and Dr Emmanuel P. Estrella who supplied their data (Reference 49).

This article is protected by copyright. All rights reserved. 


\section{References}

1. National Pressure Ulcer Advisory Panel, European Pressure Ulcer Advisory Panel and Pan Pacific Pressure Injury Alliance (NPUAP/EPUAP/PPPIA). Prevention and Treatment of Pressure Ulcers: Quick Reference Guide. Emily Haesler (Ed.). Cambridge Media: Osborne Park, Western Australia; 2014.

2. Cullum N, Buckley H, Dumville J, et al. Wounds research for patient benefit: a 5-year programme of research, Programme Grants for Applied Research. NIHR Journals Library, Southampton (UK). 2016.

3. Kaltenthaler E, Whitfield MD, Walters SJ, et al. UK, USA and Canada: how do their pressure ulcer prevalence and incidence data compare? J Wound Care. 2001; 10(1):530-5.

4. Bouten CV, Oomens CW, Baaijens FP, Bader DL. The etiology of pressure ulcers: skin deep or muscle bound? Arch Phys Med Rehabil. 2003; 84: 616-9.

5. Shi C, Dumville JC, Cullum N. Skin status for predicting pressure ulcer development: A systematic review and meta-analyses. Int J Nurs Stud. 2018; 87: 14-25.

6. Stewart LA, Clarke M, Rovers M, et al. Preferred Reporting Items for a Systematic Review and Meta-analysis of Individual Participant Data: The PRISMA-IPD Statement. JAMA. 2015; 313: $1657-65$.

7. Steyerberg EW, Moons KGM, van der Windt DA, et al. Prognosis Research Strategy (PROGRESS) 3: prognostic model research. PLoS Med. 2013; 10: e1001381.

8. Coleman S, Gorecki C, Nelson EA, et al. Patient risk factors for pressure ulcer development: systematic review. Int J Nurs Stud. 2013; 50: 974-1003.

9. McInnes E, Jammali-Blasi A, Bell-Syer SE, et al. Support surfaces for pressure ulcer prevention. Cochrane Database Syst Rev. 2015; 9: CD001735.

10. Geersing GJ, Bouwmeester W, Zuithoff $\mathrm{P}$, et al. Search filters for finding prognostic and diagnostic prediction studies in Medline to enhance systematic reviews. PLoS One. 2012; 7(2):e32844 
11. Ingui BJ, Rogers MA. Searching for clinical prediction rules in MEDLINE. J Am Med Inform Assoc. 2001; 8: 391-7.

12. Walker-Dilks C, Wilczynski NL, Haynes RB. Cumulative Index to Nursing and Allied Health Literature search strategies for identifying methodologically sound causation and prognosis studies. Appl Nurs Res. 2008; 21(2):98-103.

13. Wilczynski NL, Haynes RB. Developing optimal search strategies for detecting clinically sound prognostic studies in MEDLINE: an analytic survey. BMC Medicine. 2004; 2:23.

14. Beeckman D, Van Lancker A, Van Hecke A, Verhaeghe S. A systematic review and metaanalysis of incontinence-associated dermatitis, incontinence, and moisture as risk factors for pressure ulcer development. Res Nurs Health. 2014; 37: 204-18.

15. Gélis A, Dupeyron A, Legros P, et al. Pressure ulcer risk factors in persons with SCI: Part I: Acute and rehabilitation stages. Spinal Cord. 2009; 47: 99-107.

16. Ham W, Schoonhoven L, Schuurmans MJ, Leenen LPH. Pressure ulcers from spinal immobilization in trauma patients: a systematic review. J Trauma Acute Care Surg. 2014; 76: $1131-41$.

17. Liu P, He W, Chen HL. Diabetes mellitus as a risk factor for surgery-related pressure ulcers: a meta-analysis. J Wound Ostomy Continence Nurs. 2012; 39: 495-9.

18. Marin J, Nixon J, Gorecki C. A systematic review of risk factors for the development and recurrence of pressure ulcers in people with spinal cord injuries. Spinal Cord. 2013; 51: 522-7.

19. Michel JM, Willebois S, Ribinik P, et al. As of 2012, what are the key predictive risk factors for pressure ulcers? Developing French guidelines for clinical practice. Ann Phys Rehabil Med. 2012; 55: $454-65$.

20. Reenalda J, Jannink M, Nederhand M, IJzerman M. Clinical use of interface pressure to predict pressure ulcer development: a systematic review. Assist Technol. 2009; 21: 76-85.

21. Braden B, Bergstrom N. A conceptual schema for the study of the etiology of pressure sores. Rehabil Nurs. 1987; 12: 8-12.

22. Defloor T. The risk of pressure sores: a conceptual scheme. J Clin Nurs. 1999; 8: 206-16. 
23. Coleman S, Nixon J, Keen J, et al. A new pressure ulcer conceptual framework. J Adv Nurs. 2014; 70: 2222-34.

24. Schmid CH, Landa M, Jafar TH, et al. Constructing a database of individual clinical trials for longitudinal analysis. Control Clin Trials. 2003; 24: 324-40.

25. Hayden JA, van der Windt DA, Cartwright JL, et al. Assessing bias in studies of prognostic factors. Ann Intern Med. 2013; 158: 280-6.

26. Kristman V, Manno M, Côté P. Loss to follow-up in cohort studies: how much is too much? Eur J Epidemiol. 2004; 19: 751-60.

27. Harrell FE. Regression Modeling Strategies: With Applications to Linear Models, Logistic and Ordinal Regression, and Survival Analysis, 2nd ed. Switzerland: Springer International Publishing; 2015.

28. Turner RM, Omar RZ, Yang M, et al. A multilevel model framework for meta-analysis of clinical trials with binary outcomes. Statist Med. 2000; 19: 3417-32.

29. Kattan MW, Harrell FE. We should not be so quick to abandon the use of domain experts and full models (letter commenting: J Clin Epidemiol. 2015;71C:76--85.). J Clin Epidemiol. 2016; 75: 131.

30. StataCorp. Stata 14 Base Reference Manual. College Station, TX: Stata Press. 2015.

31. Donders ART, van der Heijden GJMG, Stijnen T, Moons KGM. Review: a gentle introduction to imputation of missing values. J Clin Epidemiol. 2006; 59: 1087-91.

32. Resche-Rigon M, White IR, Bartlett JW, et al. Multiple imputation for handling systematically missing confounders in meta-analysis of individual participant data. Stat Med. 2013; 32: 4890905.

33. Fibrinogen Studies Collaboration, Jackson D, White I, et al. Systematically missing confounders in individual participant data meta-analysis of observational cohort studies. Stat Med. 2009; 28: $1218-37$.

34. Guyatt GH, Oxman AD, Vist GE, et al. GRADE: an emerging consensus on rating quality of evidence and strength of recommendations. BMJ. 2008; 336, 924-6.

This article is protected by copyright. All rights reserved. 
35. Hahnel E, Lichterfeld A, Blume-Peytavi U, Kottner J. The epidemiology of skin conditions in the aged: A systematic review. J Tissue Viability. 2017; 26: 20-8.

36. Norton D, McLaren R, Exton-Smith AN. An investigation of geriatric nursing problems in hospital, Re-issue 1975. ed. Edinburgh; New York: Churchill Livingstone; 1962.

37. Bergquist S. Subscales, subscores, or summative score: evaluating the contribution of Braden Scale items for predicting pressure ulcer risk in older adults receiving home health care. $J$ Wound Ostomy Continence Nurs. 2001; 28(6): 279-89.

38. Nixon J, Cranny G, Bond S. Skin alterations of intact skin and risk factors associated with pressure ulcer development in surgical patients: a cohort study. Int J Nurs Stud. 2007; 44: 655-63.

39. Vanderwee K, Grypdonck M, Defloor T. Non-blanchable erythema as an indicator for the need for pressure ulcer prevention: a randomized-controlled trial. J Clin Nurs. 2007; 16: 325-35.

40. Nixon J, Cranny G, Iglesias C, et al. Randomised, controlled trial of alternating pressure mattresses compared with alternating pressure overlays for the prevention of pressure ulcers: PRESSURE (pressure relieving support surfaces) trial. BMJ. 2006; 332(7555): 1413.

41. Nixon J, Nelson EA, Cranny G, et al. Pressure relieving support surfaces: a randomised evaluation. Health Technol Assess. 2006; 10(22): iii-iv, ix-x, 1-163.

42. Allman RM. Pressure ulcers among the elderly. N Engl J Med. 1989; 320(13): 850-3.

43. Anthony D, Clark M, Dallender J. An optimization of the Waterlow score using regression and artificial neural networks. Clin Rehabil. 2000; 14(1):102-9.

44. Berlowitz DR, Ash AS, Brandeis GH, et al. Rating long-term care facilities on pressure ulcer development: importance of case-mix adjustment. Ann Intern Med. 1996; 124(6), 557-63.

45. Berlowitz DR, Brandeis GH, Morris JN, et al. Deriving a risk-adjustment model for pressure ulcer development using the Minimum Data Set. J Am Geriatr Soc. 2001; 49(7), 866-71.

46. Berlowitz DR, Brandeis GH, Anderson JJ, et al. Evaluation of a risk-adjustment model for pressure ulcer development using the Minimum Data Set. J Am Geriatr Soc. 2001; 49(7): 872-6.

47. Demarré L, Beeckman D, Vanderwee K, et al. Multi-stage versus single-stage inflation and deflation cycle for alternating low pressure air mattresses to prevent pressure ulcers in hospitalised patients: a randomised-controlled clinical trial. Int J Nurs Stud. 2012; 49: 416-26.

This article is protected by copyright. All rights reserved. 
48. Demarre L, Verhaeghe S, Van Hecke A, et al. Factors predicting the development of pressure ulcers in an at-risk population who receive standardized preventive care: secondary analyses of a multicentre randomised controlled trial. $J$ Adv Nurs. 2015; 71(2):391-403.

49. Molon JND, Estrella EP. Pressure ulcer incidence and risk factors among hospitalized orthopedic patients: results of a prospective cohort study. Ostomy Wound Manage. 2011; 57(10): 64-9.

50. Reed RL, Hepburn K, Adelson R, et al. Low serum albumin levels, confusion, and fecal incontinence: are these risk factors for pressure ulcers in mobility-impaired hospitalized adults? Gerontology. 2003; 49(4): 255-9.

51. Smith IL, Brown S, McGinnis E, et al. Exploring the role of pain as an early predictor of category 2 pressure ulcers: a prospective cohort study. BMJ Open. 2017; 7(1): e013623.

52. Nixon J, Nelson EA, Rutherford C, et al. Pressure UlceR Programme Of reSEarch (PURPOSE): using mixed methods (systematic reviews, prospective cohort, case study, consensus and psychometrics) to identify patient and organisational risk, develop a risk assessment tool and patient-reported outcome Quality of Life and Health Utility measures. Programme Grants for Applied Research. 2015; 3(6).

53. Vanderwee K, Grypdonck MHF, Defloor T. Effectiveness of an alternating pressure air mattress for the prevention of pressure ulcers. Age \& Ageing. 2005; 34(3): 261-7.

54. Riley RD, Lambert PC, Abo-Zaid G. Meta-analysis of individual participant data: rationale, conduct, and reporting. BMJ. 2010; 340: c221.

55. Riley RD, Simmonds MC, Look MP. Evidence synthesis combining individual patient data and aggregate data: a systematic review identified current practice and possible methods. J Clin Epidemiol. 2007; 60: 431.e1-431.e12.

56. Riley RD, Steyerberg EW. Meta-analysis of a binary outcome using individual participant data and aggregate data. Res Synth Method. 2010; 1: 2-19.

57. Morris TP, White IR, Carpenter JR, et al. Combining fractional polynomial model building with multiple imputation. Stat Med. 2015; 34: 3298-317.

This article is protected by copyright. All rights reserved. 
58. Hippisley-Cox J, Coupland C, Vinogradova Y, et al. Derivation and validation of QRISK, a new cardiovascular disease risk score for the United Kingdom: prospective open cohort study. BMJ. 2007; 335: 136.

59. National Institute for Health and Care Excellence (NICE). Pressure ulcers: prevention and management (Clinical guideline No. CG179). 2014; http://guidance.nice.org.uk/CG179

60. Shi C, Dumville JC, Cullum N. Evaluating the development and validation of empirically-derived prognostic models for pressure ulcer risk assessment: A systematic review. Int J Nurs Stud. 2019; 89, 88-103.

61. Beeckman D, Schoonhoven L, Fletcher J, et al. EPUAP classification system for pressure ulcers: European reliability study. $J$ Adv Nurs. 2007; 60: 682-691.

62. Vanderwee K, Grypdonck MHF, De Bacquer D, et al. The reliability of two observation methods of nonblanchable erythema, Grade 1 pressure ulcer. Appl Nurs Res. 2006; 19, 156-162.

63. React to Red Skin. Stop Pressure Ulcers. Available at: www.reacttoredskin.co.uk (last accessed 06 November 2018). 


\section{Supporting Information}

Appendix file 1: The list of factors that individual-level data were requested

Appendix file 2: Table S1. The adapted Quality In Prognosis Studies (QUIPS) tool

Appendix file 3: Methods of additional analyses

Appendix file 4: Table S2. Characteristics of included studies

Appendix file 5: Figure S1. The scatter plots of the estimated odds ratios with 95\% confidence intervals for age in years showing a non-linear relationship

Appendix file 6: Figure S2. The scatter plot of the estimated odds ratios with $95 \%$ confidence intervals for BMI in $\mathrm{kg} / \mathrm{m} 2$ showing a non-linear relationship

Appendix file 7: Figure S3. The scatter plot of the estimated odds ratios with $95 \%$ confidence intervals for Braden scores showing a non-linear relationship

Appendix file 8: Figure S4. Interaction plot of non-blanchable erythema and the ten categories of age

Appendix file 9: Figure S5. Interaction plot of non-blanchable erythema and the ten categories of Braden scores

Appendix file 10: Figure S6. Interaction plot of non-blanchable erythema and mattress types

Appendix file 11: Table S3. Comparisons of data on the included variables in the model between complete cases and cases with any missing values

This article is protected by copyright. All rights reserved. 


\section{Figure legends}

Figure 1: Flow chart of study selection

Figure 2: Risk of bias assessment

This article is protected by copyright. All rights reserved. 


\section{Table legends}

\section{Table 1: The characteristics of participants within and across the included studies}

\begin{tabular}{|c|c|c|c|c|c|}
\hline Factors ${ }^{*}$ & $\begin{array}{l}\text { Demarre et al. }{ }^{47,48} \\
(\mathrm{n}=610)\end{array}$ & $\begin{array}{l}\text { Molon and Estrella }{ }^{49}(\mathrm{n}= \\
40)\end{array}$ & $\begin{array}{l}\text { Nixon et al. }{ }^{40,41} \\
(\mathrm{n}=1,971)\end{array}$ & $\begin{array}{l}\text { Smith et al. }{ }^{51,52} \\
(\mathrm{n}=602)\end{array}$ & $\begin{array}{l}\text { Overall } \\
(\mathrm{n}=3,223)\end{array}$ \\
\hline $\begin{array}{l}\text { Number of participants with } \\
\text { incident pressure ulcers within } \\
28 \text { days - no. (\%) }\end{array}$ & $35(5.74 \%)$ & $7(17.50 \%)$ & $192(9.74 \%)$ & $149(24.75 \%)$ & $383(11.88 \%)$ \\
\hline $\begin{array}{l}\text { Number of participants with } \\
\text { incident pressure ulcers at any } \\
\text { time - no. (\%) }\end{array}$ & $35(5.74 \%)$ & $8(20.00 \%)$ & $207(10.50 \%)$ & $152(25.25 \%)$ & $402(12.47 \%)$ \\
\hline $\begin{array}{l}\text { Non-blanchable erythema - no. } \\
(\%)\end{array}$ & $94(15.41 \%)$ & $4(10.00 \%)$ & $325(16.49 \%)$ & $290(48.17 \%)$ & $713(22.12 \%)$ \\
\hline Age (years) - mean (SD) & $76.33(14.00)$ & $38.93(16.38)$ & $75.19(9.46)$ & $77.34(12.73)$ & $75.36(11.94)$ \\
\hline Missing & 0 & 0 & 0 & 0 & 0 \\
\hline \multicolumn{6}{|l|}{ Sex - no. (\%) } \\
\hline Male & $241(39.51 \%)$ & $31(77.50 \%)$ & $711(36.07 \%)$ & $233(38.70 \%)$ & $1,216(37.73 \%)$ \\
\hline Female & $369(60.49 \%)$ & $9(22.50 \%)$ & $1,260(63.93 \%)$ & $369(61.30 \%)$ & $2,007(62.27 \%)$ \\
\hline
\end{tabular}

This article is protected by copyright. All rights reserved. 


\begin{tabular}{|c|c|c|c|c|c|}
\hline Missing & 0 & 0 & 0 & 0 & \\
\hline Weight $(\mathrm{kg})$ - mean (SD) & $65.81(15.28)$ & $59.52(11.01)$ & $70.52(16.21)$ & $73.88(27.92)$ & $70.08(19.05)$ \\
\hline Missing & 0 & 0 & $185(9.39 \%)$ & $15(2.49 \%)$ & $200(6.21 \%)$ \\
\hline \multicolumn{6}{|l|}{ Weight loss - no. (\%) } \\
\hline No & $214(35.08 \%)$ & NA & $1,785(90.56 \%)$ & $454(75.41 \%)$ & $2,453(76.11 \%)$ \\
\hline Yes & $183(30.00 \%)$ & NA & $170(8.63 \%)$ & $147(24.42 \%)$ & $500(15.51 \%)$ \\
\hline Missing & $213(34.92 \%)$ & 40 & $16(0.81 \%)$ & $1(0.17 \%)$ & $270(8.38 \%)$ \\
\hline Height $(\mathrm{cm})-$ mean $(\mathrm{SD})$ & $165.77(9.54)$ & $164.2(6.78)$ & $165.26(9.20)$ & $166.23(10.60)$ & $165.52(9.52)$ \\
\hline Missing & 0 & & $45(2.28 \%)$ & 15 (2.49\%) & $60(1.86 \%)$ \\
\hline $\begin{array}{l}\text { Body mass index }\left(\mathrm{kg} / \mathrm{cm}^{2}\right)- \\
\text { mean }(\mathrm{SD})\end{array}$ & $23.83(4.65)$ & $22.09(3.98)$ & $25.76(5.22)$ & $26.71(9.50)$ & $25.50(6.25)$ \\
\hline Missing & 0 & 0 & $210(10.65 \%)$ & $24(3.99 \%)$ & $234(7.26 \%)$ \\
\hline \multicolumn{6}{|l|}{$\begin{array}{l}\text { Other skin problems (yes/no) - } \\
\text { no. }(\%)\end{array}$} \\
\hline Yes & $39(6.39 \%)$ & $10(25.00 \%)$ & $229(11.62 \%)$ & $127(21.09 \%)$ & $405(12.57 \%)$ \\
\hline No & $571(93.61 \%)$ & $30(75.00 \%)$ & $1,742(88.38 \%)$ & $474(78.74 \%)$ & $2,817(87.40 \%)$ \\
\hline Missing & 0 & 0 & 0 & $1(0.17 \%)$ & $1(0.03 \%)$ \\
\hline
\end{tabular}

This article is protected by copyright. All rights reserved. 


\begin{tabular}{|c|c|c|c|c|c|}
\hline \multicolumn{6}{|l|}{$\begin{array}{l}\text { Current pressure ulcers at Stage } \\
2 \text { or above }- \text { no. }(\%)\end{array}$} \\
\hline Yes & 0 & 0 & $113(5.73 \%)$ & $164(27.24 \%)$ & $277(8.59 \%)$ \\
\hline No & $610(100 \%)$ & $40(100 \%)$ & $1,858(94.27 \%)$ & $438(72.76 \%)$ & $2,946(91.41 \%)$ \\
\hline Missing & 0 & 0 & 0 & 0 & 0 \\
\hline \multicolumn{6}{|l|}{ Braden mobility - no. (\%) } \\
\hline Completely immobile & $87(14.26 \%)$ & $1(2.50 \%)$ & $362(18.37 \%)$ & $21(3.49 \%)$ & $471(14.61 \%)$ \\
\hline Very limited & $421(69.02 \%)$ & $7(17.50 \%)$ & $1,342(68.09 \%)$ & $262(43.52 \%)$ & $2,032(63.05 \%)$ \\
\hline Slightly limited & $87(14.26 \%)$ & $26(65.00 \%)$ & $102(5.17 \%)$ & $231(38.37 \%)$ & $446(13.84 \%)$ \\
\hline No limitations & $1(0.16 \%)$ & $6(15.00 \%)$ & $114(5.78 \%)$ & $88(14.62 \%)$ & $209(6.48 \%)$ \\
\hline Missing & $14(2.30 \%)$ & 0 & $51(2.59 \%)$ & 0 & $65(2.02 \%)$ \\
\hline \multicolumn{6}{|l|}{ Braden activity - no. $(\%)$} \\
\hline Bedfast & $165(27.05 \%)$ & $31(77.50 \%)$ & $1,558(79.05 \%)$ & $104(17.28 \%)$ & $1,858(57.65 \%)$ \\
\hline Chairfast & $366(60.00 \%)$ & $6(15.00 \%)$ & $211(10.70 \%)$ & $313(51.99 \%)$ & $896(27.80 \%)$ \\
\hline Walks occasionally & $65(10.66 \%)$ & $3(7.50 \%)$ & $51(2.59 \%)$ & $157(26.08 \%)$ & $276(8.56 \%)$ \\
\hline Walks frequently & $1(0.16 \%)$ & 0 & $101(5.12 \%)$ & $28(4.65 \%)$ & $130(4.03 \%)$ \\
\hline Missing & $13(2.13 \%)$ & 0 & $50(2.54 \%)$ & 0 & $63(1.95 \%)$ \\
\hline
\end{tabular}

This article is protected by copyright. All rights reserved. 


\begin{tabular}{|c|c|c|c|c|c|}
\hline \multicolumn{6}{|l|}{ Braden friction - no. $(\%)$} \\
\hline Problem & $248(40.66 \%)$ & $1(2.50 \%)$ & $1,176(59.66 \%)$ & $101(16.78 \%)$ & $1,526(47.35 \%)$ \\
\hline Potential problem & $326(53.44 \%)$ & $10(25.00 \%)$ & $559(28.36 \%)$ & $413(68.60 \%)$ & $1,308(40.58 \%)$ \\
\hline No apparent problem & $21(3.44 \%)$ & $29(72.50 \%)$ & $186(9.44 \%)$ & $88(14.62 \%)$ & $324(10.05 \%)$ \\
\hline Missing & $15(2.46 \%)$ & 0 & $50(2.54 \%)$ & 0 & $65(2.02 \%)$ \\
\hline Braden total score - mean (SD) & $13.30(2.30)$ & $17.78(2.50)$ & $13.63(3.14)$ & $17.17(2.30)$ & $14.29(3.20)$ \\
\hline Missing & 0 & 0 & $50(2.54 \%)$ & 0 & $50(1.55 \%)$ \\
\hline \multicolumn{6}{|l|}{ Support surface use - no. $(\%)$} \\
\hline Standard mattress & 0 & $40(100 \%)$ & 0 & $36(5.98 \%)$ & $76(2.36 \%)$ \\
\hline Reactive mattress & 0 & 0 & 0 & $273(45.35 \%)$ & $273(8.47 \%)$ \\
\hline Active air mattress & $610(100 \%)$ & 0 & $1,971(100 \%)$ & $292(48.50 \%)$ & $2,873(89.14 \%)$ \\
\hline Hybrid mattress & 0 & 0 & 0 & 0 & 0 \\
\hline Missing & 0 & 0 & 0 & $1(0.17 \%)$ & $1(0.03 \%)$ \\
\hline \multicolumn{6}{|l|}{ Diabetes - no. $(\%)$} \\
\hline Yes & $135(22.13 \%)$ & NR & $190(9.64 \%)$ & $153(25.41 \%)$ & $478(14.83 \%)$ \\
\hline No & $475(77.87 \%)$ & NR & $1,770(89.80 \%)$ & $448(74.42 \%)$ & $2,693(83.56 \%)$ \\
\hline Missing & 0 & $40(100 \%)$ & $11(0.56 \%)$ & $1(0.17 \%)$ & $52(1.61 \%)$ \\
\hline
\end{tabular}

This article is protected by copyright. All rights reserved. 


\begin{tabular}{|c|c|c|c|c|c|}
\hline \multicolumn{6}{|c|}{$\begin{array}{l}\text { Peripheral vascular disease }- \text { no. } \\
(\%)\end{array}$} \\
\hline Yes & $76(12.46 \%)$ & NR & NR & NR & $76(2.36 \%)$ \\
\hline No & $534(87.54 \%)$ & NR & NR & NR & $534(16.57 \%)$ \\
\hline Missing & 0 & $40(100 \%)$ & $1,971(100 \%)$ & $602(100 \%)$ & $2,613(81.07 \%)$ \\
\hline \multicolumn{6}{|c|}{$\begin{array}{l}\text { If any surgery is underwent } \\
\text { recently - no. (\%) }\end{array}$} \\
\hline Yes & NR & $23(57.50 \%)$ & NR & $\mathrm{NR}$ & $23(0.71 \%)$ \\
\hline No & NR & $17(42.50 \%)$ & NR & NR & $17(0.53 \%)$ \\
\hline Missing & $610(100 \%)$ & 0 & $1,971(100 \%)$ & $602(100 \%)$ & $3,183(98.76 \%)$ \\
\hline
\end{tabular}

Notes: * Among the factors we requested, only factors with any available individual participant data are summarised in this table. Across the four studies, there were data for

over $80 \%$ of participants on: non-blanchable erythema, age, body mass index, other skin problems, current pressure ulcer of Stage 2 or above, Braden scores, support surface use, weight loss, and diabetes. Skin problem is incontinence-associated dermatitis in Demarré et al. ${ }^{47,48}$, dry skin in Molon and Estrella ${ }^{49}$ and chronic wounds or others in Nixon et al. ${ }^{40,41}$ and Smith et al. ${ }^{51,52}$ Molon and Estrella ${ }^{49}$ did not collect data on weight loss, diabetes, or mattresses, but the authors claimed that all participants used standard hospital mattress.

This article is protected by copyright. All rights reserved. 
Table 2: Results of univariable and multivariable multilevel analyses using complete cases and imputed data *

\begin{tabular}{|c|c|c|c|c|}
\hline Factors & $\begin{array}{l}\text { Univariable analysis of } \\
\text { complete cases - OR }(95 \% \\
\text { CI) }\end{array}$ & $\begin{array}{l}\text { Multivariable analysis of } \\
\text { complete cases-OR }(95 \% \mathrm{CI})\end{array}$ & $\begin{array}{l}\text { Multivariable analysis of } \\
\text { imputed data (ten imputations) } \\
\text { - OR }(95 \% \mathrm{CI})\end{array}$ & $\begin{array}{l}\text { Multivariable analysis of the } \\
\text { secondary outcome data - OR } \\
(95 \% \mathrm{CI})\end{array}$ \\
\hline Total number of sample & 3,223 & 2,684 & $3,183^{* *}$ & 2,684 \\
\hline $\begin{array}{l}\text { The primary outcome: number of } \\
\text { participants with new pressure ulcers } \\
\text { within } 28 \text { days - no. }(\%)\end{array}$ & $383(11.88 \%)$ & $315(11.74 \%)$ & $376(11.81 \%)$ & Not applicable \\
\hline $\begin{array}{l}\text { The secondary outcome: number of } \\
\text { participants with new pressure ulcers } \\
\text { at any time - no. (\%) }\end{array}$ & Not applicable & Not applicable & Not applicable & $329(12.26 \%)$ \\
\hline \multicolumn{5}{|l|}{ Non-blanchable erythema } \\
\hline No (Reference) & 1 & 1 & 1 & 1 \\
\hline Yes & $\begin{array}{l}3.52(95 \% \text { CI } 2.72 \text { to } 4.56) \\
\text { Low-certainty evidence }\end{array}$ & $\begin{array}{l}2.72 \text { (95\% CI } 2.02 \text { to } 3.69) \\
\text { Moderate-certainty evidence }\end{array}$ & $2.70(95 \%$ CI 2.08 to 3.52$)$ & 2.77 (95\% CI 2.05 to 3.75$)$ \\
\hline \multicolumn{5}{|l|}{ Other skin problems } \\
\hline No (reference) & & 1 & 1 & 1 \\
\hline
\end{tabular}

This article is protected by copyright. All rights reserved. 


\begin{tabular}{|c|c|c|c|}
\hline Yes & 2.21 (95\% CI 1.63 to 2.99$)$ & 2.00 (95\% CI 1.51 to 2.66$)$ & 2.41 (95\% CI 1.79 to 3.24$)$ \\
\hline \multicolumn{4}{|l|}{$\begin{array}{l}\text { Current pressure ulcers at Stage } 2 \text { or } \\
\text { above }\end{array}$} \\
\hline No (reference) & 1 & 1 & 1 \\
\hline Yes & 1.70 (95\% CI 1.19 to 2.42$)$ & $1.50(95 \%$ CI 1.07 to 2.09$)$ & $1.62(95 \%$ CI 1.14 to 2.30$)$ \\
\hline \multicolumn{4}{|l|}{ Support surface use } \\
\hline Standard mattress (reference) & 1 & 1 & 1 \\
\hline Reactive mattress & 1.41 (95\% CI 0.55 to 3.63$)$ & 1.50 (95\% CI 0.60 to 3.77$)$ & $1.18(95 \%$ CI 0.47 to 2.93$)$ \\
\hline Active air mattress & $0.86(95 \%$ CI 0.33 to 2.24$)$ & 0.95 (95\% CI 0.37 to 2.43$)$ & 0.71 (95\% CI 0.28 to 1.81$)$ \\
\hline \multicolumn{4}{|l|}{ Weight loss } \\
\hline No (reference) & 1 & 1 & 1 \\
\hline Yes & $0.86(95 \%$ CI 0.60 to 1.24$)$ & 0.90 (95\% CI 0.65 to 1.26$)$ & 0.87 (95\% CI 0.61 to 1.24$)$ \\
\hline \multicolumn{4}{|l|}{ Diabetes } \\
\hline No (reference) & 1 & 1 & 1 \\
\hline Yes & $1.53(95 \%$ CI 1.11 to 2.12$)$ & $1.53(95 \%$ CI 1.13 to 2.07$)$ & $1.55(95 \%$ CI 1.12 to 2.13$)$ \\
\hline Age (years) ${ }^{\mathbb{I l}}$ & & Not estimable & \\
\hline Age 50 (reference) & 1 & & 1 \\
\hline
\end{tabular}

This article is protected by copyright. All rights reserved. 


\begin{tabular}{|c|c|c|c|}
\hline Age 55 & 1.01 (95\% CI 0.80 to 1.28$)$ & & $1.01(95 \%$ CI 0.80 to 1.27$)$ \\
\hline Age 60 & $1.03(95 \%$ CI 0.65 to 1.63$)$ & & $1.02(95 \%$ CI 0.65 to 1.61$)$ \\
\hline Age 65 & 1.10 (95\% CI 0.60 to 2.04$)$ & & 1.09 (95\% CI 0.59 to 2.01$)$ \\
\hline Age 70 & $1.32(95 \%$ CI 0.69 to 2.53$)$ & & 1.30 (95\% CI 0.69 to 2.48$)$ \\
\hline Age 75 & $1.75(95 \%$ CI 0.92 to 3.32$)$ & & 1.73 (95\% CI 0.92 to 3.27$)$ \\
\hline Age 80 & $2.12(95 \%$ CI 1.15 to 3.89$)$ & & 2.15 (95\% CI 1.17 to 3.94$)$ \\
\hline Age 85 & 2.25 (95\% CI 1.20 to 4.22$)$ & & 2.31 (95\% CI 1.24 to 4.32$)$ \\
\hline Age 90 & $2.23(95 \%$ CI 1.19 to 4.21$)$ & & $2.24(95 \%$ CI 1.20 to 4.21$)$ \\
\hline Age 95 & $2.19(95 \%$ CI 1.04 to 4.58$)$ & & $2.13(95 \%$ CI 1.02 to 4.43$)$ \\
\hline Age 100 & 2.14 (95\% CI 0.84 to 5.46$)$ & & 2.01 (95\% CI 0.80 to 5.10$)$ \\
\hline Body mass index $\left(\mathrm{kg} / \mathrm{cm}^{2}\right)^{\text {IT }}$ & & Not estimable & \\
\hline $\begin{array}{l}\text { Body mass index } 20 \\
\text { (reference) }\end{array}$ & 1 & & 1 \\
\hline Body mass index 22 & 0.98 (95\% CI 0.86 to 1.11$)$ & & 0.96 (95\% CI 0.85 to 1.09$)$ \\
\hline Body mass index 24 & $0.92(95 \%$ CI 0.67 to 1.26$)$ & & $0.95(95 \%$ CI 0.70 to 1.28$)$ \\
\hline Body mass index 26 & $0.86(95 \%$ CI 0.59 to 1.26$)$ & & $0.89(95 \%$ CI 0.62 to 1.28$)$ \\
\hline Body mass index 28 & $0.82(95 \%$ CI 0.59 to 1.15$)$ & & $0.82(95 \%$ CI 0.59 to 1.14$)$ \\
\hline
\end{tabular}

This article is protected by copyright. All rights reserved. 


\begin{tabular}{|c|c|c|c|}
\hline Body mass index 30 & $0.81(95 \%$ CI 0.57 to 1.15$)$ & & 0.78 (95\% CI 0.55 to 1.10$)$ \\
\hline Body mass index 32 & $0.81(95 \%$ CI 0.56 to 1.18$)$ & & 0.77 (95\% CI 0.54 to 1.11$)$ \\
\hline Body mass index 34 & $0.83(95 \%$ CI 0.58 to 1.21$)$ & & $0.79(95 \%$ CI 0.54 to 1.14$)$ \\
\hline Braden total score $^{\mathbb{T}}$ & & Not estimable & \\
\hline Score 23 (reference) & 1 & & 1 \\
\hline Score 6 & $0.85(95 \%$ CI 0.17 to 4.21$)$ & & $1.12(95 \%$ CI 0.24 to 5.24$)$ \\
\hline Score 7 & $1.14(95 \%$ CI 0.29 to 4.49$)$ & & 1.49 (95\% CI 0.40 to 5.59$)$ \\
\hline Score 8 & $1.55(95 \%$ CI 0.49 to 4.91$)$ & & $1.98(95 \%$ CI 0.64 to 6.11$)$ \\
\hline Score 9 & $2.09(95 \%$ CI 0.78 to 5.60$)$ & & 2.63 (95\% CI 0.99 to 6.96$)$ \\
\hline Score 10 & $2.82(95 \%$ CI 1.17 to 6.80$)$ & & 3.49 (95\% CI 1.45 to 8.42$)$ \\
\hline Score 11 & $3.69(95 \%$ CI 1.57 to 8.68$)$ & & 4.49 (95\% CI 1.90 to 10.60$)$ \\
\hline Score 12 & $3.99(95 \%$ CI 1.71 to 9.29$)$ & & $4.71(95 \%$ CI 2.01 to 11.04$)$ \\
\hline Score 13 & $3.20(95 \%$ CI 1.45 to 7.07$)$ & & $3.62(95 \%$ CI 1.63 to 8.05$)$ \\
\hline Score 14 & 2.39 (95\% CI 1.09 to 5.24$)$ & & 2.62 (95\% CI 1.19 to 5.79$)$ \\
\hline Score 15 & $2.11(95 \%$ CI 0.94 to 4.75$)$ & & 2.31 (95\% CI 1.02 to 5.25$)$ \\
\hline Score 16 & $2.05(95 \%$ CI 0.87 to 4.87$)$ & & 2.29 (95\% CI 0.96 to 5.47$)$ \\
\hline Score 17 & $1.97(95 \%$ CI 0.82 to 4.74$)$ & & 2.21 (95\% CI 0.91 to 5.35$)$ \\
\hline
\end{tabular}

This article is protected by copyright. All rights reserved. 


\begin{tabular}{|c|c|c|}
\hline Score 18 & $1.82(95 \%$ CI 0.80 to 4.16$)$ & $2.03(95 \%$ CI 0.89 to 4.67$)$ \\
\hline Score 19 & $1.65(95 \%$ CI 0.81 to 3.35$)$ & $1.81(95 \%$ CI 0.88 to 3.70$)$ \\
\hline Score 20 & $1.46(95 \%$ CI 0.84 to 2.54$)$ & $1.57(95 \%$ CI 0.90 to 2.74$)$ \\
\hline Score 21 & $1.29(95 \%$ CI 0.89 to 1.87$)$ & $1.36(95 \%$ CI 0.93 to 1.97$)$ \\
\hline Score 22 & $1.14(95 \%$ CI 0.94 to 1.37$)$ & $1.16(95 \%$ CI 0.97 to 1.40$)$ \\
\hline
\end{tabular}

Notes: $*$ degree of freedom for all multivariable analyses $=19 ; * *$ All 40 cases in Molon and Estrella ${ }^{49}$ were not included after imputed data analysis because data on weight loss and diabetes were not collected;

II Continuous data of age, body mass index, and Braden total score were modelled using the restricted cubic spline method; their odds ratios in the table were for some selected values of these continuous data, which was only for the purpose of presenting potential non-linear relationship (see Appendix files 5-7: Figs S1 to S3 for the graphical presentations of the results). For the imputed data analysis (i.e., the analysis in the third column of the table), the odds ratios for the selected values of the three continuous factors cannot be calculated using the current STATA package though restricted cubic splines of the three factors can be done in the analysis.

This article is protected by copyright. All rights reserved. 


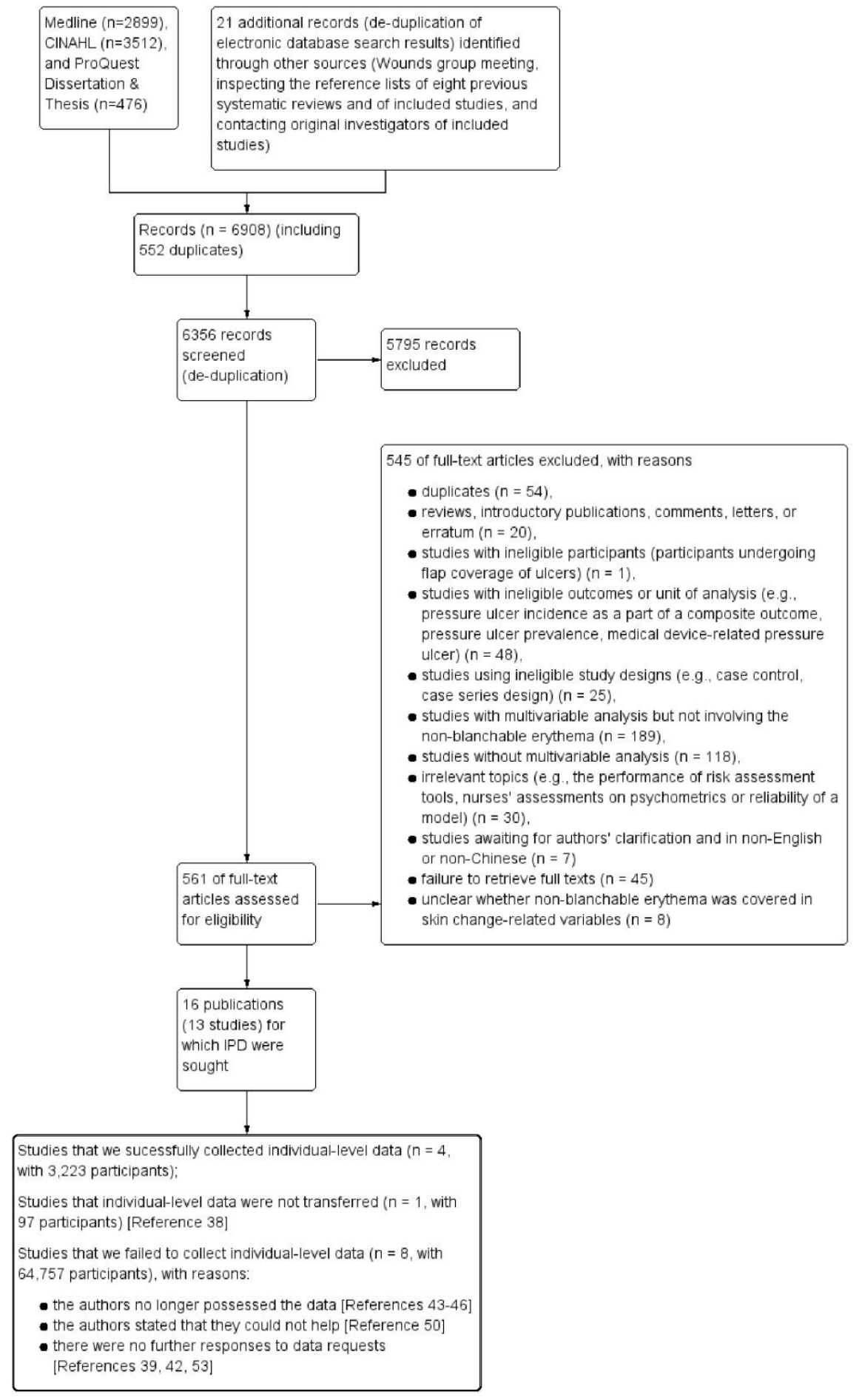

This article is protected by copyright. All rights reserved. 


\begin{tabular}{|c|c|c|c|c|c|c|}
\hline & 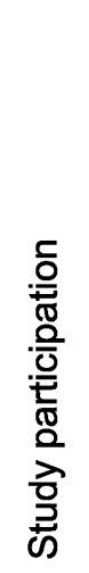 & 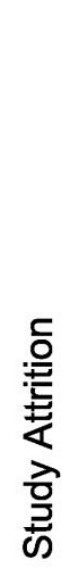 & 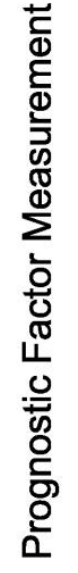 & 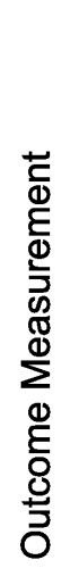 & 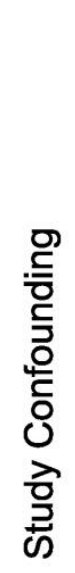 & 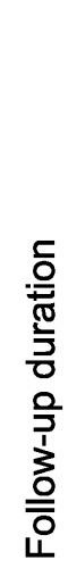 \\
\hline Allman 1995 [42] & + & + & $?$ & $?$ & $?$ & 4 \\
\hline Anthony 2000 [43] & + & $?$ & + & & $?$ & + \\
\hline Berlowitz 1996 [44] & + & + & 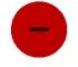 & $?$ & $?$ & 4 \\
\hline Berlowitz 2001 [45] & + & & $?$ & $?$ & $?$ & \\
\hline Berlowitz 2001 [46] & $?$ & 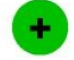 & $?$ & $?$ & $?$ & 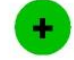 \\
\hline Demarre $2015[47,48]$ & + & \pm & + & + & + & \\
\hline Molon and Estrella 2011 [49] & + & ( & + & $?$ & + & \\
\hline Nixon $2006[40,41]$ & 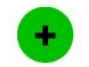 & & + & + & + & \\
\hline Nixon 2007 [38] & $?$ & $?$ & + & $?$ & $?$ & $?$ \\
\hline Reed 2003 [50] & + & + & $?$ & $?$ & & 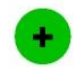 \\
\hline Smith $2017[51,52]$ & & & + & $?$ & + & 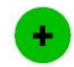 \\
\hline Vanderwee 2005 [53] & + & 4 & + & $?$ & $?$ & $?$ \\
\hline Vanderwee 2007 [39] & + & + & + & $?$ & $?$ & $?$ \\
\hline
\end{tabular}

